\title{
Predicting gene expression using DNA methylation in three human populations
}

\author{
Huan Zhong ${ }^{1}$, Soyeon Kim ${ }^{2}$, Degui Zhi ${ }^{2}$, Xiangqin Cui ${ }^{\text {Corresp. } 3}$ \\ 1 Department of Biology, Hong Kong Baptist University, Hong Kong, China \\ 2 School of Biomendical Informatics, University of Texas Health Center at Houston, Houston, Texas, United States \\ 3 Department of Biostatistics and Bioinformatics, Emory University, Atlanta, Georgia, United States \\ Corresponding Author: Xiangqin Cui \\ Email address: xiangqin.cui@emory.edu
}

Background. DNA methylation, an important epigenetic mark, is well known for its regulatory role in gene expression, especially the negative regulation in the promoter region. However, its correlation with gene expression across individuals at human population level has not been well studied. In particular, it is unclear if genome-wide DNA methylation profile of an individual can predict her/his gene expression profile. Previous studies were mostly limited to association analyses between single $\mathrm{CpG}$ site methylation and gene expression. It is not known whether DNA methylation of a gene has enough prediction power to serve as a surrogate for gene expression in existing human study cohorts with DNA samples other than RNA samples.

Results. We examined DNA methylation in the gene region for predicting gene expression across individuals in non-cancer tissues of three human population datasets, adipose tissue of the Multiple Tissue Human Expression Resource Projects (MUTHER), peripheral blood mononuclear cell (PBMC) from Asthma and normal control study participates, and lymphoblastoid cell lines $(\mathrm{LCL})$ from healthy individuals. Three prediction models were investigated, single linear regression, multiple linear regression, and least absolute shrinkage and selection operator (LASSO) penalized regression. Our results showed that LASSO regression has superior performance among these methods. However, the prediction power is generally low and varies across datasets. Only 30 and 42 genes were found to have cross-validation $\mathrm{R}^{2}$ greater than 0.3 in the PBMC and Adipose datasets, respectively. A substantially larger number of genes (258) were identified in the $\mathrm{LCL}$ dataset, which was generated from a more homogeneous cell line sample source. We also demonstrated that using all CpG probes on the methylation array improves the prediction power regardless whether they measure DNA methylation, cross hybridization, or SNP effect. 
Conclusion. In human populations, DNA methylation of CpG sites at gene region seems to have limited prediction power for gene expression across individuals. The prediction power potentially varies depending on tissue, cell type, and data sources. In our analyses, the combination of LASSO regression and all probes on the methylation array provides the best prediction for gene expression. 


\section{Predicting gene expression using DNA methylation in three}

\section{2 human populations}

3

4 Huan Zhong ${ }^{1}$, Soyeon $\mathrm{Kim}^{2}$, Degui Zhi ${ }^{2}$, Xiangqin $\mathrm{Cui}^{3}$

5

$6 \quad{ }^{1}$ Department of Biology, Hong Kong Baptist University, HONG KONG

$7{ }^{2}$ School of Biomedical Informatics, University of Texas Health Science Center at Houston,

8 Houston, TX, USA

$9 \quad{ }^{3}$ Department of Biostatistics and Bioinformatics, Emory University, Atlanta, Georgia, USA

11 Corresponding author: Xiangqin Cui

12 Email: xiangqin.cui@emory.edu 


\section{Abstract}

\section{Background}

16 DNA methylation, an important epigenetic mark, is well known for its regulatory role in gene

17 expression, especially the negative regulation in the promoter region. However, its correlation

18 with gene expression across individuals at human population level has not been well studied. In

19 particular, it is unclear if genome-wide DNA methylation profile of an individual can predict

20 her/his gene expression profile. Previous studies were mostly limited to association analyses

21 between single $\mathrm{CpG}$ site methylation and gene expression. It is not known whether DNA

22 methylation of a gene has enough prediction power to serve as a surrogate for gene expression in

23 existing human study cohorts with DNA samples other than RNA samples.

\section{Results}

25 We examined DNA methylation in the gene region for predicting gene expression across

26 individuals in non-cancer tissues of three human population datasets, adipose tissue of the

27 Multiple Tissue Human Expression Resource Projects (MuTHER), peripheral blood

28 mononuclear cell (PBMC) from Asthma and normal control study participates, and

29 lymphoblastoid cell lines (LCL) from healthy individuals. Three prediction models were

30 investigated, single linear regression, multiple linear regression, and least absolute shrinkage and

31 selection operator (LASSO) penalized regression. Our results showed that LASSO regression has

32 superior performance among these methods. However, the prediction power is generally low and

33 varies across datasets. Only 30 and 42 genes were found to have cross-validation $\mathrm{R}^{2}$ greater than

340.3 in the PBMC and Adipose datasets, respectively. A substantially larger number of genes

35 (258) were identified in the LCL dataset, which was generated from a more homogeneous cell 
36 line sample source. We also demonstrated that using all $\mathrm{CpG}$ probes on the methylation array

37 improves the prediction power regardless whether they measure DNA methylation, cross

38 hybridization, or SNP effect.

\section{Conclusion}

40 In human populations, DNA methylation of $\mathrm{CpG}$ sites at gene region seems to have limited

41 prediction power for gene expression across individuals. The prediction power potentially varies

42 depending on tissue, cell type, and data sources. In our analyses, the combination of LASSO

43 regression and all probes on the methylation array provides the best prediction for gene

44 expression.

\section{Background}

DNA methylation has long been recognized as an important epigenetic modification in regulating gene expression (Razin \& Riggs, 1980). This process often occurs at CG dinucleotides sites (CpG sites), adding a methyl group to the cytosine residue (You \& Jones, 2012; Wagner et al., 2015). In mammalian genomes, more than $70 \%$ of CpG sites are methylated (Jabbari \& Bernardi, 2004). Many CpGs are clustered into CpG islands and more than 30,000 CpG islands have been identified in the human genome, most of which are located in promoter region and are hypo-methylated (Jeziorska et al., 2017). The level of DNA methylation at a CpG site is often correlated with that of neighbouring $\mathrm{CpG}$ sites and influenced by other genome features, such as genome position and regulatory elements. When combined, these genome features can

57 effectively predict methylation level of CpG sites in the genome (Zheng et al., 2017). 
59 The regulatory role of DNA methylation on gene expression has traditionally been studied with a

60 small number of $\mathrm{CpG}$ sites in a limited number of genes. The more recent application of

61 microarrays and next generation sequencing enables large-scale analysis of DNA methylation

62 and gene expression across the whole genome (Krueger et al., 2012). However, most human

63 genome-wide methylation and expression studies in non-cancer tissues have small sample sizes

64 for comparing controlled groups. Only a limited number of studies profiled both genome-wide

65 DNA methylation and gene expression in larger human populations and examined their

66 relationship across individuals. Del Rey et al., (Del Rey et al., 2013) studied the genome-wide

67 DNA methylation and gene expression in 83 low-risk subtypes of Myelodysplastic syndrome

68 (MDS) patients and 36 controls using microarrays. They found negative correlations between

69 methylation and gene expression across individuals in a large proportion of differentially

70 expressed and differentially methylated genes, but they also uncovered substantial positive

71 correlations. In another study of 648 twins, overall negative correlations were found in the

72 adipose tissue, promoter region (-0.018), gene body (-0.013) and 3-prime UTR (-0.007)

73 (Grundberg et al., 2013). More recently, Wagner et al.(Wagner et al., 2014) profiled the genome

74 wide DNA methylation and gene expression in forearm skin fibroblast among 62 unrelated

75 individuals. They observed that the association between gene expression and methylation is not

76 always negative in promoter region or positive in gene body (Yang et al., 2014).

78 The complex relationship among DNA methylation, gene expression, and genetic variants in

79 human populations has also attracted substantial research attention. Bell et al., (Bell et al., 2011)

80 investigated the genetic controls for both methylation QTL (mQTL) and expression QTL (eQTL) 
81 using 77 human lymphoblastoid cell lines (LCLs) from the HapMap collection. They identified

82 hundreds of mQTLs and eQTLs and showed that these two types of QTLs overlap significantly.

83 Gutierrez et al. (Gutierrez-Arcelus et al., 2013) further examined the relationship among genetic

84 variants, DNA methylation, and gene expression in three cell types of umbilical cord samples

85 from 204 newborn babies and found that the relationship between DNA methylation and gene

86 expression across individuals has a different process from that across genes with in a genome.

87 The inter-individual relationship is much less clear in terms of negative regulation. Both active

88 and passive roles are played by DNA methylation in regulating gene expression.

90 Unlike genome-wide DNA methylation, the inter-individual relationship between genetic

91 variants and gene expression in human populations has been well-studied in both eQTL

92 identification (Deelen et al., 2015) and gene expression prediction (Xie et al., 2017; Zeng, Zhou

93 \& Huang, 2017).. Predicted gene expression is also used as an instrument in genome wide

94 association studies to reduce multiple testing and identify associated genes (Gamazon et al.,

95 2015). Similar studies in DNA methylation is lacking since previous studies were mostly limited

96 to association analyses between single $\mathrm{CpG}$ site methylation and gene expression. It is not

97 known whether DNA methylation of a gene has enough prediction power when all CpGs are

98 considered together to serve as a surrogate for gene expression or enable gene expression to be

99 an instrument in genome wide methylation studies in human populations. In this study, we

100 examine the DNA methylation and gene expression relationship in three large human datasets.

101 We determine the overall relationship between DNA methylation and gene expression across

102 individuals for each gene and evaluate the predictive potential of DNA methylation data for gene

103 expression. We also demonstrate that a penalized regression improves the overall prediction. 


\section{Methods}

106 1) Datasets:

107 Adipose Dataset

108 This dataset is from the MuTHER study, consisting of 856 female European-descent individuals

109 enrolled in the TwinsUK Adult Twin Registry. The quartile normalized gene expression and

110 DNA methylation data from subcutaneous fat were downloaded from ArrayExpress

111 (http://www.ebi.ac.uk/arrayexpress/). The gene expression data (accession number E-TABM-

112 1140) were generated for 25160 genes using Illumina HumanHT-12 v3.0 on 825 individuals.

113 The $\log 2$-transformed signals were quantile normalized for each tissue followed by quantile

114 normalized across the whole population(Grundberg et al., 2012). The DNA methylation data

115 (accession number E-MTAB-1866) were generated using Illumina Infinium Human

116 Methylation450 from 649 female twins. The methylation beta values were already quantile

117 normalized for each type of probe, ranging from 0 (unmethylated) to 1 (total-methylated).

119 PBMC Dataset

120 This dataset was downloaded from Gene Expression Ominbus (GSE40736). It includes 194

121 inner-city children with 97 cases of atopy and persistent asthma and 97 healthy controls. All the

122 study participants were 6 to 12 years old from African American, Dominican-Hispanic and

123 Haitian-Hispanic background(Yang et al., 2015). DNA methylation data were generated using

124 Illumina’s Infinium Human Methylation450k BeadChip. The normalized methylation M value 
125 matrix was downloaded from

126 ftp://ftp.ncbi.nlm.nih.gov/geo/series/GSE40nnn/GSE40576/matrix/. Gene expression data were

127 generated for 23612 genes using Nimblegen Human Gene Expression arrays (12x135k). The

128 normalized data matrix was downloaded from

129 ftp://ftp.ncbi.nlm.nih.gov/geo/series/GSE40nnn/GSE40732/matrix/. According to the

130 publication, one outlier sample has been removed after principle component analysis, SWAN

131 normalization was used for methylation data. Log2 transformation and RMA normalization were

132 used for gene expression data. For each gene, expression level was standardized across samples.

\section{LCL Dataset}

135 The LCL dataset was generated from Lymphoblastoid cell lines (LCL) of 280 healthy

136 individuals (96 Han Chinese-American, 96 Caucasian-American and 95 African-American).

137 Data were downloaded from GSE23120 and GSE36369

138 (https://www.ncbi.nlm.nih.gov/geo/query/acc.cgi?acc=GSE36369

139 https://www.ncbi.nlm.nih.gov/geo/query/acc.cgi?acc=GSE23120

140 ). Gene expression microarray data were generated using Affymetrix Human Genome U133 Plus

1412.0 Array, which contains 38,500 well-characterized human genes covered by 54,000 probe sets

142 (https://www.affymetrix.com/support/technical/datasheets/human_datasheet.pdf) DNA

143 methylation data were generated using Infinium HumanMethylation450 BeadChip platform.

144 Quantile normalized M values were used in the analyses. 
147 To assess the DNA methylation effect in prediction gene expression, we defined the

148 "methylation probes" as the 344,303 probes in Table S1 of the Grundberg's paper. The probes on

149 the methylation array but excluded from the Table S1, which have potential SNP effects or cross

150 hybridization effects, are termed "S\&C probes". The combinations of these two types of probes

151 are termed "all probes". The Adipose dataset has 32,478 missing values in the DNA

152 methylation data. Samples with missing values were excluded from regression analysis of the

153 respective gene. Among the 485679 probes in the dataset, 344201 probes remained in Adipose

154 dataset after filtering. For the PBMC dataset, 344180 out of the 485461 probes in the dataset

155 remained after filtering and 344202 out of 485578 probes remained for the LCL dataset. In order

156 to make the method comparable and the analysis consistent, only genes that have the LASSO

157 models were used, 8040 genes and $149152 \mathrm{CpG}$ sites in Adipose dataset, 4251 genes and 73553

158 CpG sites in PBMC dataset and 7514 genes and 143599 CpG sites in LCL dataset. (Table S1).

160 3) Modelling the relationship between gene expression and DNA methylation.

$161 \mathrm{CpG}$ probes were mapped to genes using UCSC RefGene annotation. Gene expression and DNA

162 methylation data for each gene were extracted using in-house perl script. Since there was no

163 missing value for methylation of the PBMC and LCL dataset, all samples were used in the

164 regression analysis.

165

166 We used three types of regressions, single linear regression, multiple regression, and least

167 absolute shrinkage and selection operator (LASSO) regression(Tibshirani, 1996), to model the

168 linear relationship between gene expression and DNA methylation. Squared correlation $\left(\mathrm{R}^{2}\right)$ 
169 between predicted and observed data was used to compare the three types of regressions. In the

170 single linear regression, each $\mathrm{CpG}$ site was modeled separately to predict gene expression level.

171 The $\mathrm{CpG}$ site that provides maximum $\mathrm{R}^{2}$ was used to represent each gene. In multiple

172 regressions, all the CpG sites in each gene were used as predictors and the $\mathrm{R}^{2}$ was calculated. In

173 the LASSO regression with default parameters, all $\mathrm{CpG}$ sites were used to predict the gene

174 expression. We used the GLMNET package in R to fit the LASSO model in which penalized 175 parameters were obtained using 10-fold cross-validation to minimize the mean squared error, 176 while the predictors and response variables were all standardized.

\section{4) Cross validation}

179 In addition to calculating the $\mathrm{R}^{2}$ from fitting the models (fitting $\mathrm{R}^{2}$ ), we also conducted five-fold 180 cross validation to compare the prediction power of the three regression models using the 181 validation $R^{2}\left(R^{2} . c v\right)$. Specifically, the samples were randomly separated into training set (4/5 of

182 data) and testing set (1/5 of data). The procedure was iterated 10 times and the mean $\mathrm{R}^{2}$ of the 10

183 five-fold cross validations was used as our final cross validation $\mathrm{R}^{2}$ for each model. For single

184 regression, cross validation was conducted for each $\mathrm{CpG}$ site and the maximum $\mathrm{R}^{2}$ was used for

185 each gene. For LASSO regression analysis, we first obtained the optimal penalty parameter using

186 ten-fold cross validation and then used another five-fold cross validation to evaluate the

187 predictive performance of the model.

188 Note that we calculated fitting $\mathrm{R}^{2}$ in the LASSO cross validation models. We used the entire

189 datasets as testing in the LASSO cross validation models in order to obtain the fitting R2 in a 
190 fashion consistent with the multiple and single cross-validation models. In this case, all the R2

191 values in the paper are squared correlation of the predicted and the true values in the training set.

\section{5) Model comparisons on significant genes}

193 We first identified genes that showed overall model prediction p values less than 0.0001 in

194 multiple regressions and then compared the three regression models on these genes.

\section{6) Gene Ontology (GO) and pathway enrichment analysis.}

196 For top 2000 genes with highest $\mathrm{R}^{2}$, we use The Database for Annotation, Visualization and

197 Integrated Discovery (DAVID ) at https://david.ncifcrf.gov/ (Huang, Sherman \& Lempicki,

198 2008) to conduct GO term enrichment analysis based on modified Fisher Exact Test. The

199 background genes were set to be the genes on the expression array, HumanHT-12_V3_0_

200 R2_11283641_A. The significantly overrepresented GO terms were selected based on the EASE

201 Score, which is the geometric mean of p-values on logarithm scale for the member terms. We

202 applied medium classification stringency in the DAVID website to our data.

203 "GOTERM_BP_FAT" was used to obtain more information in biological processes of the Gene

204 Ontology enrichment analysis. "KEGG_PATHWAY" was selected for pathway enrichment

205 analysis in the same fashion. The most enriched GO terms and pathways with low p-value or

206 FDR were shown in the results.

7) Gene expression prediction using different type of probes on the methylation microarray

208 The probes excluded by Table S1 of the Grundberg's paper were treated as probes with SNP

209 and/or hybridization effects (S\&C probes). We compared these probes, the methylation probes,

210 and the combination of these two types of probes in predicting gene expression. 


\section{8) Analysis codes}

212 We wrapped up our major analysis codes into a package at

213 https://github.com/dorothyzh/MethylXcan. It includes all three regressions and calculates the

214 squared correlation for each model. The package is written in R and Perl, and has been tested

215 under linux or MACSOX system. Users can use this package on the datasets described here or on

216 their own data after formatting their methylation data, expression profiling data, and annotation

217 files as specified by the package.

218

219 Results

220

221

222

223

224

225

226

227

228

229

230

231

232

233

Association between single $\mathrm{CpG}$ methylation and gene expression is often conducted in human populations when both transcriptome and methylome are profiled. In this study we set out to find whether combining all $\mathrm{CpG}$ sites in a gene can better predict the gene expression in a human population. We obtained three human datasets, an Adipose dataset generated from subcutaneous fat tissue, a PBMC dataset from Childhood Asthma study, and a lymphoblastoid cell line (LCL) dataset. To evaluate the predicting power of DNA methylation on gene expression, we conducted three types of linear regression analyses, single regression, multiple regression, and LASSO regression for each gene. Squared correlation $\left(\mathrm{R}^{2}\right)$ was used for model comparisons. To focus on DNA methylation effect, we first left out $\mathrm{CpG}$ probes that overlap SNPs or cross-hybridize to multiple locations (S\&C probes). In addition, since some genes fail to establish a LASSO model due to the lack of predictive information in DNA methylation, we only focus on genes with valid LASSO models for comparing different regression methods. In the three datasets, the total number of genes varies from 26,736 to 32,946 after quality control and normalization. About $1 / 6$ 
234 to $1 / 3$ of these genes have valid LASSO models with slightly bigger numbers when S\&C probes

235 are included (Table 1). In general, a large fraction of the genes with LASSO models have

236 prediction $\mathrm{R}^{2}$ greater than 0.1 , but the number of genes quick reduces to hundreds and tens when

$237 \mathrm{R}^{2}$ increases to 0.2 and 0.3 (Table 1).

238

239 Multiple regressions using all methylation CpGs from a gene predict gene expression the 240 best in model fitting.

242 As a reference, we first conducted association analysis on each methylation probe in predicting 243 gene expression using single regression. Most of the genes with valid LASSO models have at

244 least one significant $\mathrm{CpG}$ at nominal significance level of 0.05. For example, in the Adipose

245 dataset, 7326 out of 8040 genes have at least one $\mathrm{CpG}$ site significant at 0.05 level and 3460 out

246 of 8040 genes have at least one $\mathrm{CpG}$ site significant at 0.0001 . However, the prediction power

247 represented by the largest $\mathrm{R}^{2}$ in each gene is generally low. Only 19 genes have $\mathrm{R}^{2}$ greater than

$248 \quad 0.3$ and 486 genes have $\mathrm{R}^{2}$ larger than 0.1 when the most predictive $\mathrm{CpG}$ site is considered

249 (Table 1). Similar results were obtained from the PBMC and LCL datasets, except that the

250 PBMC dataset has a substantially smaller number of genes with a $\mathrm{CpG}$ significant at 0.0001 level

251 (582 out of 4252 genes) although the distribution of the estimated $\mathrm{R}^{2}$ is similar to that from the

252 Adipose dataset. This could be due to the smaller sample size or the nature of the PBMC tissue

253 source. On the other hand, the LCL dataset has a larger number of genes with higher $\mathrm{R}^{2}$ from

254 single $\mathrm{CpG}$ regression analysis, which could be related to the homogeneous nature of cell lines. 255 
256 Since multiple $\mathrm{CpG}$ sites from each gene were assayed on the methylation microarray, we

257 applied multiple linear regression to utilize all methylation $\mathrm{CpG}$ sites in the gene region as

258 predictors simultaneously. The $\mathrm{R}^{2}$ explained by the regression model did improve substantially

259 for the majority of genes compared with that from the single linear regression (Fig. 1). As

260 expected, the significant genes from multiple regression analyses tend to have larger $\mathrm{R}^{2}$

261 compared with the non-significant genes. The improvement of $\mathrm{R}^{2}$ from the multiple regression

262 over single regress in the PBMC and LCL datasets is similar to that in the Adipose dataset (Fig. 263 1).

265 Compared with multiple regressions, LASSO regression did not generate $\mathrm{R}^{2}$ quite as high in all

266 datasets (Fig. 1 D-F), which is also indicated by smaller number of genes with $\mathrm{R}^{2}$ exceeding

267 each threshold (Table 1). For example, the number of genes with $\mathrm{R}^{2}$ greater than 0.2 decreased

268 from 476 to 360 for the Adipose dataset, from 1163 to 561 for the PBMC datasets, and from

2692170 to 1704 for the LCL dataset. Similar trend was observed at the other two thresholds for all

270 three datasets.

271

272 It is widely recognized that gene expression is negatively correlated with DNA methylation level

273 in the promoter region but often positively correlated with DNA methylation level in gene body

274 (Ball et al., 2009; Wu et al., 2010; Jones, 2012). The different directions of correlation among

$275 \mathrm{CpG}$ sites in the same gene may lead to perceptions that combining all $\mathrm{CpG}$ sites is not

276 advantageous in the prediction of gene expression. However, the multiple and lasso regressions

277 can accommodate coefficients in different directions without affecting prediction power. 
278 Nevertheless, we tested CpG sites from promoter region and those from gene body for prediction

279 separately in the LCL dataset. As expected, neither performs as well as combined (Fig. S1).

280

281 LASSO regression shows better prediction in cross-validation.

282

283 To better assess the accuracy of the predictive models, we performed 5-fold cross validation on 284 single, multiple regressions, and LASSO regressions to estimate the prediction $\mathrm{R}^{2}$. The results 285 showed that the LASSO regression produced much larger $\mathrm{R}^{2}$ values than the single regression 286 and less dramatic but discernible increases over multiple regressions (Fig. 2). These differences 287 are also reflected in the number of genes with $\mathrm{R}^{2}$ exceeding the three thresholds. For example, 288827 genes (10.29\%) from the Adipose dataset have $\mathrm{R}^{2}$ greater than 0.1 from LASSO regression, 289 while 722 genes (8.98\%) and 106 genes $(1.32 \%)$ have $\mathrm{R}^{2}$ greater than 0.1 from multiple 290 regression and single regression, respectively (Table 1). For genes with $\mathrm{R}^{2}$ greater than 0.3 , 291 LASSO regression has 42 genes $(0.52 \%)$ while multiple regression and single regression have 38 $292(0.47 \%)$ and 2 genes $(0.02 \%)$, respectively. These results indicate that penalized regression has

293 better prediction than multiple or single regressions in cross-validation. Cross validation tends to 294 overcome bias and over-fitting issues. As expected, cross-validation $\mathrm{R}^{2}$ values are generally

295 lower than those from the model fittings, which is reflected by the smaller number of genes with $296 \mathrm{R}^{2}$ values greater than the $\mathrm{R}^{2}$ thresholds (Table 1). Similar results were obtained from the PBMC 297 dataset and the LCL dataset.

298

299 To make sure that the prediction $\mathrm{R}^{2}$ is larger than thoses from random chance, we compared the 300 cumulative $\mathrm{R}^{2}$ from the three datasets with those from the the null distribution of correlations 
301 based on Fisher z-transfromation in quantile-quantile plots (Fig. 3). All datasets showed that the

302 observed $\mathrm{R}^{2}$ values are much larger than the expected $\mathrm{R}^{2}$ values from random chance. In

303 addition, the departure is the largest in the LCL dataset followed by the Adipose dataset and the

304 PBMC dataset when methylation probes were considered, indicating that the LASSO models

305 capture a larger proportion of the transcriptome variability in the LCL dataset than in the other

306 two datasets. This is potentially due to the combination of sample size and nature of different

307 tissues.

308

309 To rule out the possibility that prediction $\mathrm{R}^{2}$ is mainly driven by the variability of gene

310 expression and the variability of DNA methylation across individuals in the study population, we

311 first examined the correlation between the variability of gene expression with $\mathrm{R}^{2}$ from LASSO

312 regression. No obvious correlation was observed (Fig. S2). For assessing the correlation

313 between DNA methylation variability and prediction $\mathrm{R}^{2}$, we took the CpG with maximum $\mathrm{R}^{2}$

314 from single regression and examined the correlation between its variability with the prediction

$315 \mathrm{R}^{2}$ from LASSO regression. We only observed a potential positive correlation in the Adipose

316 dataset when the $\mathrm{R}^{2}$ is greater than 0.5 , where there are a small number of genes (Fig. S3).

318 Using all probes improves prediction power for gene expression

320 In order to evaluate DNA methylation power in predicting gene expression, we first left out a

321 large proportion of probes potentially affected by genetic or cross-hybridization effects (Table

322 S1). However, using all probes on the array is preferred if our goal is to achieve better prediction

323 accuracy of gene expression. To evaluate the prediction power from all probes, we included all 
324 available probes in LASSO regression and found that the overall prediction power did increase

325 compared to the models using only the methylation probes (Fig. 3). We observed more genes

326 with $\mathrm{R}^{2}$ values exceeding the thresholds (Table 1). In addition, the largest $\mathrm{R}^{2}$ value is much

327 larger when all probes are used compared to that from only the methylation probes. For example,

328 the largest $\mathrm{R}^{2}$ is 0.92 from all probes compared to 0.74 from only methylation probes in the

329 Adipose dataset. Similarly, the largest $\mathrm{R}^{2}$ increases from 0.71 to 0.88 in the PBMC dataset and

330 from 0.76 to 0.87 in the LCL dataset. Furthermore, valid LASSO models are available for more

331 genes when all probes are used (Fig. S4).

332

333 The increase of prediction power on gene expression from all types of probes on the methylation

334 microarray suggests that there is contribution from the probes with potential SNP effects or cross

335 hybridization effects. To further assess the size and nature of their contribution, we separately

336 estimated the prediction power of the methylation probes, S\&C probes, and the combination of

337 them (all probes). The results showed that the $\mathrm{S} \& \mathrm{C}$ probes have independent prediction power

338 from the methylation probes and the combination of both has increased prediction power over

339 the methylation probes alone (red points vs black line in in Fig. 4 A C and E). The prediction

340 power from the $\mathrm{S} \& \mathrm{C}$ probes was also estimated for genes with enough SNP probes to form a

341 LASSO model and their prediction power are mostly above zero (blue points in Fig. 4). The fact

342 that the blue points are randomly distributed instead of following the black line suggests that the

343 two sources of $\mathrm{R}^{2}$ are not correlated; therefore, the genetic effect and epigenetic effect do not

344 seem to coexist in the same genes. Figure 5 shows some examples of genes with large prediction

345 powers from either methylation probes or $\mathrm{S} \& \mathrm{C}$ probes. As expected, the methylation probes tend

346 to show continuous methylation values while the $\mathrm{S} \& \mathrm{C}$ probes tend to show categorical values

347 due to limited genotypes of the samples. 
349 GO term analysis of better predicted genes

350 To examine the potential biological function of the genes showing relatively higher

351 predictability, we conducted gene ontology (GO) enrichment analysis using DAVID on genes

352 with $\mathrm{R}^{2}$ larger than 0.2 from LASSO regression of methylation CpGs. At false discovery rate

353 (FDR) of 0.01, cell adhesion, lipids metabolism, and regulation of immune system are among the

354 most significantly enriched terms in the Adipose dataset (Table S2), which seem to be consistent

355 with the previous findings for subcutaneous fat cells (Berg and Scherer 2005). For the PBMC

356 dataset, the most significantly enriched terms are mostly related to defense and immune

357 functions, lymphocyte aggregation, T cell activation, inflammatory response, as well as cell

358 adhesion. These results appear to be reasonable for atopy and persistent asthma blood cells. For

359 the LCL data, some terms related to cell adhesion, migration, communication, and

360 morphogenesis are highly enriched. Same GO term analyses were also conducted for $\mathrm{R}^{2}$ from all

361 CpG probes and similar results were obtained.

363 Discussion

364 We examined the relationship between gene expression and DNA methylation across the genome

365 using data from three large human studies. We explored three linear regression models for

366 predicting gene expression and found that shrinkage based LASSO multiple regression provides

367 the best prediction. However, even with LASSO regression, the methylation probes can predict

368 expression in only a small proportion of genes with moderate prediction power. We also

369 demonstrated that using all probes on the methylation array does improve prediction power to

370 some degree. 
372 Three types of regression models were examined in our study for their prediction power

373 evaluated by squared correlation $\left(\mathrm{R}^{2}\right)$. The single linear regression is based only on the best

374 predictive $\mathrm{CpG}$ in each gene, therefore, has least prediction power. The multiple regression has

375 increased power when all $\mathrm{CpG}$ sites in each gene are included as predictors; however, it has

376 substantial over-fitting problem for genes with large number of CpGs. The shrinkage based

377 LASSO regression overcomes the over-fitting problem without losing predictability. LASSO

378 imposes sparsity among the coefficients and puts constraint on the overall absolute values of the

379 regression coefficients, which forces certain coefficients to be zero. This property is beneficial in

380 avoiding model overfit as well as variable selection and model interpretability. In this study, not

381 all expressed genes have LASSO models because LASSO fails to select informative predictors in

382 some genes even with minimum penalization, which indicates that no predictive information

383 exists in the DNA methylation data at these genes. LASSO is not the only shrinkage-based

384 regression method. There are other penalty regression models, such as the Ridge (Hoerl \&

385 Kennard, 1970), elastic net (Zou \& Hastie, 2005), elastic net with rescaled-coefficients and

386 grouped lasso (Yuan \& Lin, 2006; Meier, Van De Geer \& Bühlmann, 2008), as well as other

387 variants of LASSO (Zou et al., 2013). Further evaluation is needed for their merits in improving

388 prediction in this setting.

389

390 The prediction power from DNA methylation in our analysis seems to be much lower than that

391 from DNA sequence variants evaluated in different human tissues (Gamazon et al., 2015). One

392 potential reason for relative low prediction power we observed from DNA methylation is the

393 complex mechanisms of gene expression regulation. In addition to DNA methylation, 
394 transcription factors, histone modification(Verdin \& Ott, 2015), and non-coding RNAs

395 (Janowski et al., 2005; Ting et al., 2005; Ting, McGarvey \& Baylin, 2006; Kaikkonen, Lam \&

396 Glass, 2011) all play critical roles in gene transcription regulation (Jones, 2015). Some more

397 comprehensive tools, such as FEM (Jiao, Widschwendter \& Teschendorff, 2014) and

398 ROADMAP (Kundaje et al., 2015), may help integrate the influences of the other factors on gene

399 expression. Another potential reason for low prediction power of methylation is that the

400 landscape of DNA methylation differs dramatically across cell types, tissues (Lokk et al., 2014),

401 ages (Teschendorff et al., 2010), and races (Song et al., 2015). The relationship between gene

402 expression and DNA methylation could also vary substantially across these factors. The

403 correlation between gene expression and DNA methylation from bulk studies at population level

404 encompasses all these variabilities; therefore, it is not surprising to see lower prediction power in

405 the PBMC and adipose datasets compared to the LCL dataset. The potential of DNA methylation

406 alone as surrogate for gene expression is likely to be limited in general, especially in the tissues

407 with mixed cell types, such as PBMC, which is used widely in human population studies. The

408 combination of DNA methylation and genotype, should be more powerful for this purpose, as

409 indicated by the increased prediction power when SNP-containing probes were included in the

410 prediction models (Fig. 3 and Fig. 4). This can be a promising future direction.

411

\section{Conclusions}

413 We explored three regression methods to predict gene expression using DNA methylation, single

414 regressions, multiple regressions, and LASSO penalized regression. LASSO regression reduces

415 over-fitting and improved the prediction power. All three datasets we analysed show relatively

416 low prediction power. The better predictive genes are dataset specific and their function varies in 
417 different tissues or cell types. Overall, we will recommend caution for using one's methylation

418 profile to predict one's transcriptome.

419

420

\section{List of Abbreviations}

422

423 SNP: single nucleotide polymorphisms

424 LASSO: least absolute shrinkage and selection operator

425 R2: squared correlation

426 S\&C: the probes have potential SNP effects or cross hybridization effects

427 MuTHER: Multiple Tissue Human Expression Resource Project

428 PBMC: peripheral blood mononuclear cell

429 LCL: lymphoblastoid cell

430 MDS: myelodysplastic syndrome

431 GO: gene ontology

432

\section{Declarations}

\section{Consent for publication}

435 All authors have read the final draft and consented for publication.

436 


\section{Availability of data and material}

438 For Adipose Dataset, both gene expression and DNA methylation data can be found at

439 http://www.ebi.ac.uk/arrayexpress/

440 For PBMC Dataset, gene expression data are at

441 ftp:/ftp.ncbi.nlm.nih.gov/geo/series/GSE40nnn/GSE40732/matrix/., while DNA methylation

442 data are at ftp://ftp.ncbi.nlm.nih.gov/geo/series/GSE40nnn/GSE40576/matrix/.

443 For LCL Dataset, gene expression data are at

444 https:/www.ncbi.nlm.nih.gov/geo/query/acc.cgi?acc=GSE23120, while DNA methylation data

445 are at

446 https://www.ncbi.nlm.nih.gov/geo/query/acc.cgi?acc=GSE36369

447

448 Software package, 'MethylXcan' are at https://github.com/dorothyzh/MethylXcan. 


\section{References}

451 Ball MP, Li JB, Gao Y, Lee J-H, LeProust EM, Park I-H, Xie B, Daley GQ, Church GM. 2009.

452 Targeted and genome-scale strategies reveal gene-body methylation signatures in human $453 \quad$ cells. Nat Biotechnol 27:361-368.

454 Bell JT, Pai AA, Pickrell JK, Gaffney DJ, Pique-Regi R, Degner JF, Gilad Y, Pritchard JK.

455 2011. DNA methylation patterns associate with genetic and gene expression variation in $456 \quad$ HapMap cell lines. Genome Biol 12:R10.

457 Deelen P, Zhernakova D V., de Haan M, van der Sijde M, Bonder MJ, Karjalainen J, van der 458 Velde KJ, Abbott KM, Fu J, Wijmenga C, Sinke RJ, Swertz MA, Franke L. 2015. Calling genotypes from public RNA-sequencing data enables identification of genetic variants that affect gene-expression levels. Genome Medicine 7. DOI: 10.1186/s13073-015-0152-4.

Gamazon ER, Wheeler HE, Shah KP, Mozaffari S V, Aquino-Michaels K, Carroll RJ, Eyler AE, Denny JC, Nicolae DL, Cox NJ. 2015. A gene-based association method for mapping traits using reference transcriptome data. Nat Genet 47:1091-1098.

Grundberg E, Meduri E, Sandling JK, Hedman ÅK, Keildson S, Buil A, Busche S, Yuan W, Nisbet J, Sekowska M. 2013. Global analysis of DNA methylation variation in adipose tissue from twins reveals links to disease-associated variants in distal regulatory elements. The American Journal of Human Genetics 93:876-890.

Grundberg E, Small KS, Hedman ÅK, Nica AC, Buil A, Keildson S, Bell JT, Yang T-P, Meduri E, Barrett A. 2012. Mapping cis-and trans-regulatory effects across multiple tissues in twins. Nat Genet 44:1084-1089.

Gutierrez-Arcelus M, Lappalainen T, Montgomery SB, Buil A, Ongen H, Yurovsky A, Bryois J, Giger T, Romano L, Planchon A, Falconnet E, Bielser D, Gagnebin M, Padioleau I, Borel C, Letourneau A, Makrythanasis P, Guipponi M, Gehrig C, Antonarakis SE, Dermitzakis ET. 2013. Passive and active DNA methylation and the interplay with genetic variation in gene regulation. eLife 2013:1-18. DOI: 10.7554/eLife.00523.

Hoerl AE, Kennard RW. 1970. Ridge regression: Biased estimation for nonorthogonal problems. Technometrics 12:55-67.

Huang DW, Sherman BT, Lempicki RA. 2008. Systematic and integrative analysis of large gene lists using DAVID bioinformatics resources. Nature protocols 4:44. 
480

481

482

483

484

485

486

487

488

489

490

491

492

493

494

495

496

497

498

499

500

501

502

503

504

505

506

507

508

509

510

Jabbari K, Bernardi G. 2004. Cytosine methylation and CpG, TpG (CpA) and TpA frequencies. Gene 333:143-149. DOI: 10.1016/j.gene.2004.02.043.

Janowski BA, Huffman KE, Schwartz JC, Ram R, Hardy D, Shames DS, Minna JD, Corey DR. 2005. Inhibiting gene expression at transcription start sites in chromosomal DNA with antigene RNAs. Nat Chem Biol 1:216-222.

Jeziorska DM, Murray RJS, De Gobbi M, Gaentzsch R, Garrick D, Ayyub H, Chen T, Li E, Telenius J, Lynch M, Graham B, Smith AJH, Lund JN, Hughes JR, Higgs DR, Tufarelli C. 2017. DNA methylation of intragenic $\mathrm{CpG}$ islands depends on their transcriptional activity during differentiation and disease. Proceedings of the National Academy of Sciences 114:E7526-E7535. DOI: 10.1073/pnas.1703087114.

Jiao Y, Widschwendter M, Teschendorff AE. 2014. A systems-level integrative framework for genome-wide DNA methylation and gene expression data identifies differential gene expression modules under epigenetic control. Bioinformatics (Oxford, England) 30:2360-6. DOI: 10.1093/bioinformatics/btu316.

Jones PA. 2012. Functions of DNA methylation: islands, start sites, gene bodies and beyond. Nature reviews. Genetics 13:484-92. DOI: 10.1038/nrg3230.

Jones B. 2015. Gene expression: Layers of gene regulation. Nat Rev Genet 16:128-129. DOI: $10.1038 / \mathrm{nrg} 3918$.

Kaikkonen MU, Lam MTY, Glass CK. 2011. Non-coding RNAs as regulators of gene expression and epigenetics. Cardiovascular research 90:430-440.

Krueger F, Kreck B, Franke A, Andrews SR. 2012. DNA methylome analysis using short bisulfite sequencing data. Nat Methods 9:145-151.

Kundaje A, Meuleman W, Ernst J, Bilenky M, Yen A, Heravi-Moussavi A, Kheradpour P, Zhang Z, Wang J, Ziller MJ, Amin V, Whitaker JW, Schultz MD, Ward LD, Sarkar A, Quon G, Sandstrom RS, Eaton ML, Wu Y-C, Pfenning A, Wang X, ClaussnitzerYaping Liu M, Coarfa C, Alan Harris R, Shoresh N, Epstein CB, Gjoneska E, Leung D, Xie W, David Hawkins R, Lister R, Hong C, Gascard P, Mungall AJ, Moore R, Chuah E, Tam A, Canfield TK, Scott Hansen R, Kaul R, Sabo PJ, Bansal MS, Carles A, Dixon JR, Farh K-H, Feizi S, Karlic R, Kim A-R, Kulkarni A, Li D, Lowdon R, Elliott G, Mercer TR, Neph SJ, Onuchic V, Polak P, Rajagopal N, Ray P, Sallari RC, Siebenthall KT, Sinnott-Armstrong NA, Stevens M, Thurman RE, Wu J, Zhang B, Zhou X, Abdennur N, Adli M, Akerman M, 
511 Barrera L, Antosiewicz-Bourget J, Ballinger T, Barnes MJ, Bates D, Bell RJA, Bennett DA,

512 Bianco K, Bock C, Boyle P, Brinchmann J, Caballero-Campo P, Camahort R, Carrasco-

513 Alfonso MJ, Charnecki T, Chen H, Chen Z, Cheng JB, Cho S, Chu A, Chung W-Y, Cowan

514 C, Athena Deng Q, Deshpande V, Diegel M, Ding B, Durham T, Echipare L, Edsall L,

515 Flowers D, Genbacev-Krtolica O, Gifford C, Gillespie S, Giste E, Glass IA, Gnirke A,

516 Gormley M, Gu H, Gu J, Hafler DA, Hangauer MJ, Hariharan M, Hatan M, Haugen E, He

517 Y, Heimfeld S, Herlofsen S, Hou Z, Humbert R, Issner R, Jackson AR, Jia H, Jiang P,

518 Johnson AK, Kadlecek T, Kamoh B, Kapidzic M, Kent J, Kim A, Kleinewietfeld M,

519 Klugman S, Krishnan J, Kuan S, Kutyavin T, Lee A-Y, Lee K, Li J, Li N, Li Y, Ligon KL,

520 Lin S, Lin Y, Liu J, Liu Y, Luckey CJ, Ma YP, Maire C, Marson A, Mattick JS, Mayo M, McMaster M, Metsky H, Mikkelsen T, Miller D, Miri M, Mukame E, Nagarajan RP, Neri F, Nery J, Nguyen T, O’Geen H, Paithankar S, Papayannopoulou T, Pelizzola M, Plettner P, Propson NE, Raghuraman S, Raney BJ, Raubitschek A, Reynolds AP, Richards H, Riehle K, Rinaudo P, Robinson JF, Rockweiler NB, Rosen E, Rynes E, Schein J, Sears R, Sejnowski T, Shafer A, Shen L, Shoemaker R, Sigaroudinia M, Slukvin I, Stehling-Sun S, Stewart R, Subramanian SL, Suknuntha K, Swanson S, Tian S, Tilden H, Tsai L, Urich M, Vaughn I, Vierstra J, Vong S, Wagner U, Wang H, Wang T, Wang Y, Weiss A, Whitton H, Wildberg A, Witt H, Won K-J, Xie M, Xing X, Xu I, Xuan Z, Ye Z, Yen C, Yu P, Zhang X, Zhang X, Zhao J, Zhou Y, Zhu J, Zhu Y, Ziegler S, Beaudet AE, Boyer LA, De Jager PL, Farnham PJ, Fisher SJ, Haussler D, Jones SJM, Li W, Marra MA, McManus MT, Sunyaev S, Thomson JA, Tlsty TD, Tsai L-H, Wang W, Waterland RA, Zhang MQ, Chadwick LH, Bernstein BE, Costello JF, Ecker JR, Hirst M, Meissner A, Milosavljevic A, Ren B, Stamatoyannopoulos JA, Wang T, Kellis M, Kundaje A, Meuleman W, Ernst J, Bilenky M, Yen A, Heravi-Moussavi A, Kheradpour P, Zhang Z, Wang J, Ziller MJ, Amin V, Whitaker JW, Schultz MD, Ward LD, Sarkar A, Quon G, Sandstrom RS, Eaton ML, Wu Y-C, Pfenning AR, Wang X, Claussnitzer M, Liu Y, Coarfa C, Harris RA, Shoresh N, Epstein CB, Gjoneska E, Leung D, Xie W, Hawkins RD, Lister R, Hong C, Gascard P, Mungall AJ, Moore R, Chuah E, Tam A, Canfield TK, Hansen RS, Kaul R, Sabo PJ, Bansal MS, Carles A, Dixon JR, Farh K-H, Feizi S, Karlic R, Kim A-R, Kulkarni A, Li D, Lowdon R, Elliott G, Mercer TR, Neph SJ, Onuchic V, Polak P, Rajagopal N, Ray P, Sallari RC, Siebenthall KT, Sinnott-Armstrong NA, Stevens M, Thurman RE, Wu J, Zhang B, Zhou X, Beaudet 
542

543

544

545

546

547

548

549

550

551

552

553

554

555

556

557

558

559

560

561

562

563

564

565

566

567

568

569

570

571

AE, Boyer LA, De Jager PL, Farnham PJ, Fisher SJ, Haussler D, Jones SJM, Li W, Marra MA, McManus MT, Sunyaev S, Thomson JA, Tlsty TD, Tsai L-H, Wang W, Waterland RA, Zhang MQ, Chadwick LH, Bernstein BE, Costello JF, Ecker JR, Hirst M, Meissner A, Milosavljevic A, Ren B, Stamatoyannopoulos JA, Wang T, Kellis M. 2015. Integrative analysis of 111 reference human epigenomes. Nature 518:317-330. DOI:

10.1038 /nature 14248 .

Lokk K, Modhukur V, Rajashekar B, Märtens K, Mägi R, Kolde R, Koltšina M, Nilsson TK, Vilo J, Salumets A. 2014. DNA methylome profiling of human tissues identifies global and tissue-specific methylation patterns. Genome Biol 15:3248.

Meier L, Van De Geer S, Bühlmann P. 2008. The group lasso for logistic regression. Journal of the Royal Statistical Society: Series B (Statistical Methodology) 70:53-71.

Razin A, Riggs AD. 1980. DNA methylation and gene function. Science 210:604-610. DOI: $10.1126 /$ science. 6254144 .

Del Rey M, O’Hagan K, Dellett M, Aibar S, Colyer HAA, Alonso ME, Diez-Campelo M, Armstrong RN, Sharpe DJ, Gutierrez NC. 2013. Genome-wide profiling of methylation identifies novel targets with aberrant hypermethylation and reduced expression in low-risk myelodysplastic syndromes. Leukemia 27:610-618.

Song M-A, Brasky TM, Marian C, Weng D, Taslim C, Dumitrescu RG, Llanos AA, Freudenheim JL, Shields PG. 2015. Racial differences in genome-wide methylation profiling and gene expression in breast tissues from healthy women. Epigenetics:0.

Teschendorff AE, Menon U, Gentry-Maharaj A, Ramus SJ, Weisenberger DJ, Shen H, Campan M, Noushmehr H, Bell CG, Maxwell AP. 2010. Age-dependent DNA methylation of genes that are suppressed in stem cells is a hallmark of cancer. Genome Res 20:440-446.

Tibshirani R. 1996. Regression shrinkage and selection via the lasso. Journal of the Royal Statistical Society. Series B (Methodological):267-288.

Ting AH, McGarvey KM, Baylin SB. 2006. The cancer epigenome-components and functional correlates. Genes Dev 20:3215-3231.

Ting AH, Schuebel KE, Herman JG, Baylin SB. 2005. Short double-stranded RNA induces transcriptional gene silencing in human cancer cells in the absence of DNA methylation. Nat Genet 37:906-910. 
572 Verdin E, Ott M. 2015. 50 years of protein acetylation: from gene regulation to epigenetics,

573

574

575

576

577

578

579

580

581

582

583

584

585

586

587

588

589

590

591

592

593

594

595

596

597

598

599

600

601

602

metabolism and beyond. Nature Reviews Molecular Cell Biology 16:258-264.

Wagner JR, Busche S, Ge B, Kwan T, Pastinen T, Blanchette M. 2014. The relationship between DNA methylation, genetic and expression inter-individual variation in untransformed human fibroblasts. Genome Biol 15:R37.

Wagner JR, Busche S, Ge B, Kwan T, Pastinen T, Blanchette M, Grundberg E, Meduri E, Sandling JK, Hedman ÅK, Keildson S, Buil A, Busche S, Yuan W, Nisbet J, Sekowska M, Hoerl AE, Kennard RW, Huang DW, Sherman BT, Tan Q, Kir J, Liu D, Bryant D, Guo Y, Stephens R, Baseler MW, Lane HC, Ting AH, McGarvey KM, Baylin SB, Razin A, Riggs AD, Zou H, Hastie T, Tibshirani R, Del Rey M, O'Hagan K, Dellett M, Aibar S, Colyer HAA, Alonso ME, Diez-Campelo M, Armstrong RN, Sharpe DJ, Gutierrez NC, Bayarsaihan D, Deng C, Yang J, Scott J, Hanash S, Richardson BC, Gamazon ER, Wheeler HE, Shah KP, Mozaffari S V, Aquino-Michaels K, Carroll RJ, Eyler AE, Denny JC, Nicolae DL, Cox NJ, Gao H, Lukin K, Ramírez J, Fields S, Lopez D, Hagman J, Gorelik G, Richardson BC, Grundberg E, Small KS, Hedman ÅK, Nica AC, Buil A, Keildson S, Bell JT, Yang T-P, Meduri E, Barrett A, Janowski BA, Huffman KE, Schwartz JC, Ram R, Hardy D, Shames DS, Minna JD, Corey DR, Jones B, Kaikkonen MU, Lam MTY, Glass CK, Krueger F, Kreck B, Franke A, Andrews SR, Lokk K, Modhukur V, Rajashekar B, Märtens K, Mägi R, Kolde R, Koltšina M, Nilsson TK, Vilo J, Salumets A, Majumder P, Boss JM, Meier L, Van De Geer S, Bühlmann P, Robertson KD, Scharer CD, Barwick BG, Youngblood BA, Ahmed R, Boss JM, Seguín-Estévez Q, De Palma R, Krawczyk M, Leimgruber E, Villard J, Picard C, Tagliamacco A, Abbate G, Gorski J, Nocera A, Song MA, Brasky TM, Marian C, Weng D, Taslim C, Dumitrescu RG, Llanos AA, Freudenheim JL, Shields PG, Spector TD, Williams FMK, Suárez-Álvarez B, Rodriguez RM, Calvanese V, Blanco-Gelaz MA, Suhr ST, Ortega F, Otero J, Cibelli JB, Moore H, Fraga MF, Teschendorff AE, Menon U, Gentry-Maharaj A, Ramus SJ, Weisenberger DJ, Shen H, Campan M, Noushmehr H, Bell CG, Maxwell AP, Tibshirani R, Ting AH, Schuebel KE, Herman JG, Baylin SB, Verdin E, Ott M, Yang I V, Pedersen BS, Liu A, O'Connor GT, Teach SJ, Kattan M, Misiak RT, Gruchalla R, Steinbach SF, Szefler SJ, You JS, Jones PA, Yuan M, Lin Y. 2015. DNA methylation and human disease. Journal of the Royal Statistical Society: Series B (Statistical Methodology) 12:906-910. DOI: 10.1038/nrg3918. 
603 Wu H, Coskun V, Tao J, Xie W, Ge W, Yoshikawa K, Li E, Zhang Y, Sun YE. 2010. Dnmt3a604 dependent nonpromoter DNA methylation facilitates transcription of neurogenic genes.

605 Science 329:444-447. DOI: 10.1126/science.1190485.

606

Xie R, Wen J, Quitadamo A, Cheng J, Shi X. 2017. A deep auto-encoder model for gene 607 expression prediction. BMC Genomics 18. DOI: 10.1186/s12864-017-4226-0.

608

Yang X, Han H, De Carvalho DD, Lay FD, Jones PA, Liang G. 2014. Gene body methylation

609 can alter gene expression and is a therapeutic target in cancer. Cancer cell 26:577-590.

Yang I V, Pedersen BS, Liu A, O’Connor GT, Teach SJ, Kattan M, Misiak RT, Gruchalla R,

611 Steinbach SF, Szefler SJ. 2015. DNA methylation and childhood asthma in the inner city.

612 Journal of Allergy and Clinical Immunology 136:69-80.

613

You JS, Jones PA. 2012. Cancer genetics and epigenetics: two sides of the same coin? Cancer cell 22:9-20.

Yuan M, Lin Y. 2006. Model selection and estimation in regression with grouped variables. Journal of the Royal Statistical Society: Series B (Statistical Methodology) 68:49-67.

Zeng P, Zhou X, Huang S. 2017. Prediction of gene expression with cis-SNPs using mixed models and regularization methods. BMC Genomics 18. DOI: 10.1186/s12864-017-3759-6. wide DNA methylation in repetitive elements. Nucleic Acids Res 45:8697-8711. DOI: $10.1093 / \mathrm{nar} / \mathrm{gkx} 587$.

Zou H, Hastie T. 2005. Regularization and variable selection via the elastic net. Journal of the Royal Statistical Society: Series B (Statistical Methodology) 67:301-320. McGarvey KM, Baylin SB, Tibshirani R, Razin A, Riggs AD, Hoerl AE, Kennard RW, Grundberg E, Meduri E, Sandling JK, Hedman ÅK, Keildson S, Buil A, Busche S, Yuan W, Nisbet J, Sekowska M, Del Rey M, O’Hagan K, Dellett M, Aibar S, Colyer HAA, Alonso ME, Diez-Campelo M, Armstrong RN, Sharpe DJ, Gutierrez NC. 2013. Regression shrinkage and selection via the lasso. Journal of the Royal Statistical Society. Series B (Methodological) 12:R37. DOI: 10.1126/science.6254144. 
Figure 1

$\mathrm{R}^{2}$ comparison among three regression models.

Multiple regression is compared to single (top three panels) and lasso (bottom three panels) regressions in three datasets, $\operatorname{Adipose}(A, D), \operatorname{PBMC}(B, E)$ and $L C L(C, F) . R^{2}$ values shown here are on cubic root scale for visualization clarity. "single", single linear regression with the most significant CpG site as predictor; "multiple", multiple regression with all methylation CpG sites in a gene as predictors. Red points represent significant genes from multiple regressions at significance level of 0.0001 . Blue solid line is the identity line and the dashed lines represent $R^{2}$ of 0.1 .
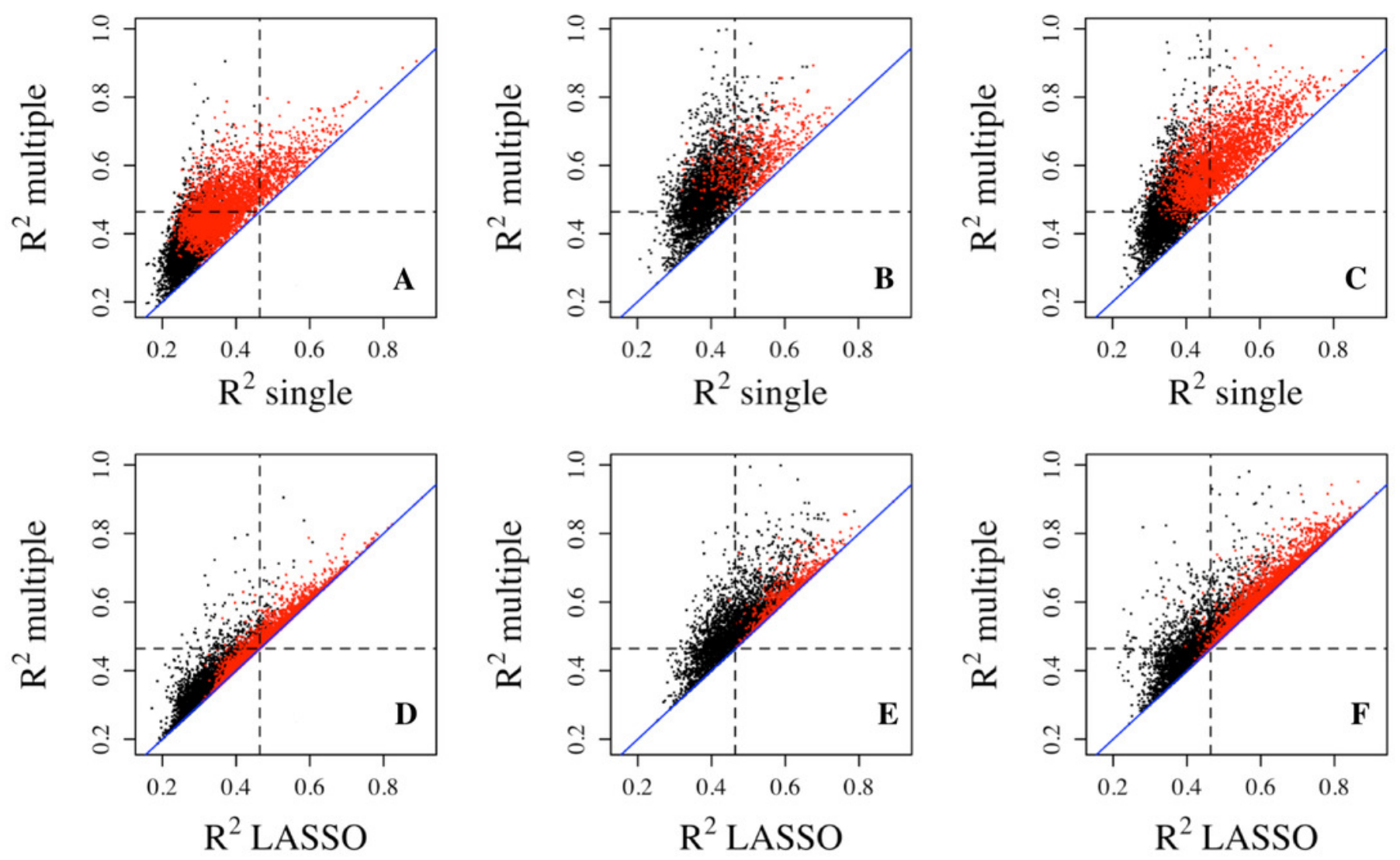


\section{Figure 2}

$\mathrm{R}^{2}$ comparison among regression models in cross validation.

Cross-validation $\mathrm{R}^{2}$ from LASSO regression are compared to those from single regression (top three panels) and multiple regression (bottom three panels) for three datasets, Adipose( $A$, $D), \operatorname{PBMC}(B, E)$ and $L C L(C, F)$. Five-fold validation was used for all regression models. $R^{2}$ shown here are on cubic root scale for visualization clarity. The red points represent the significant genes from multiple regressions $(p<0.0001)$. Blue solid line is the identity line and the dashed lines represent $R^{2}$ of 0.1 . single.cv, cross-validation $R^{2}$ of single regression; multiple.cv, cross-validation $\mathrm{R}^{2}$ of multiple regression; cross-validation $\mathrm{R}^{2}$ of LASSO regression.
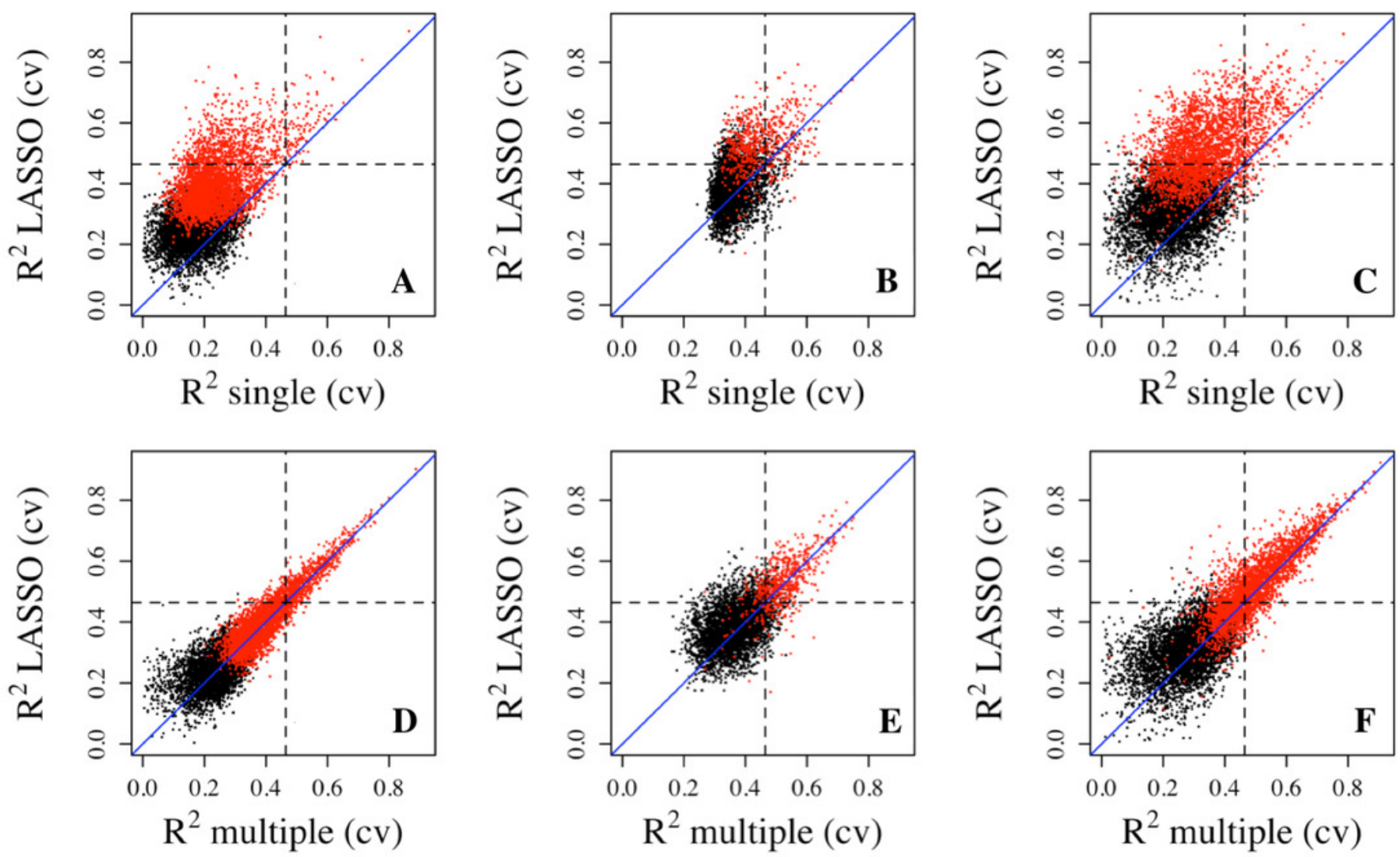


\section{Figure 3}

The prediction $\mathrm{R}^{2}$ is beyond random chance.

Sorted $R^{2}$ values from three datasets, Adipose $(A, B), \operatorname{PBMC}(C, D)$ and $L C L(E, F)$, are compared with those from the null distribution of $\mathrm{R}^{2}$ based on Fisher z-transformation (straight line). Panels on the left are from the methylation probes alone. Panels on the right are from all probes. Five-fold cross validation was used for LASSO regression models. 
Methyl Probes
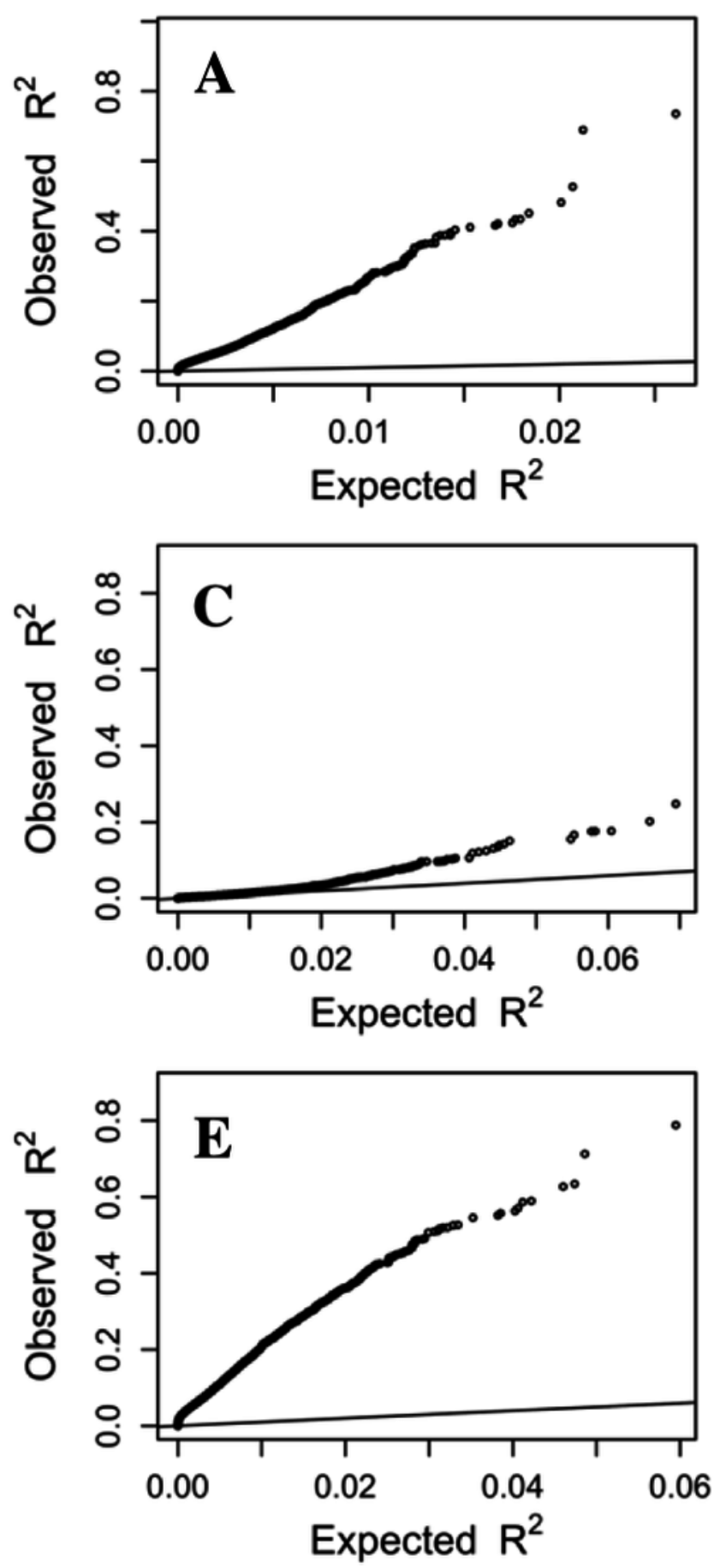

All Probes

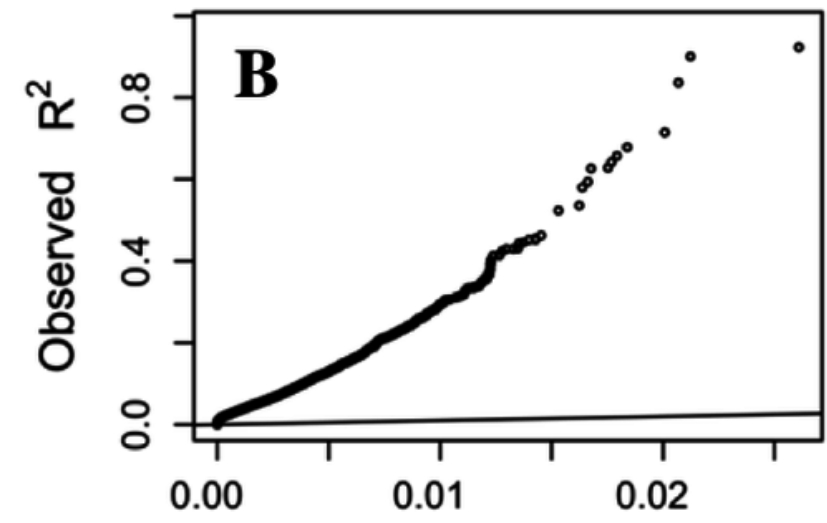

Expected $\mathrm{R}^{2}$
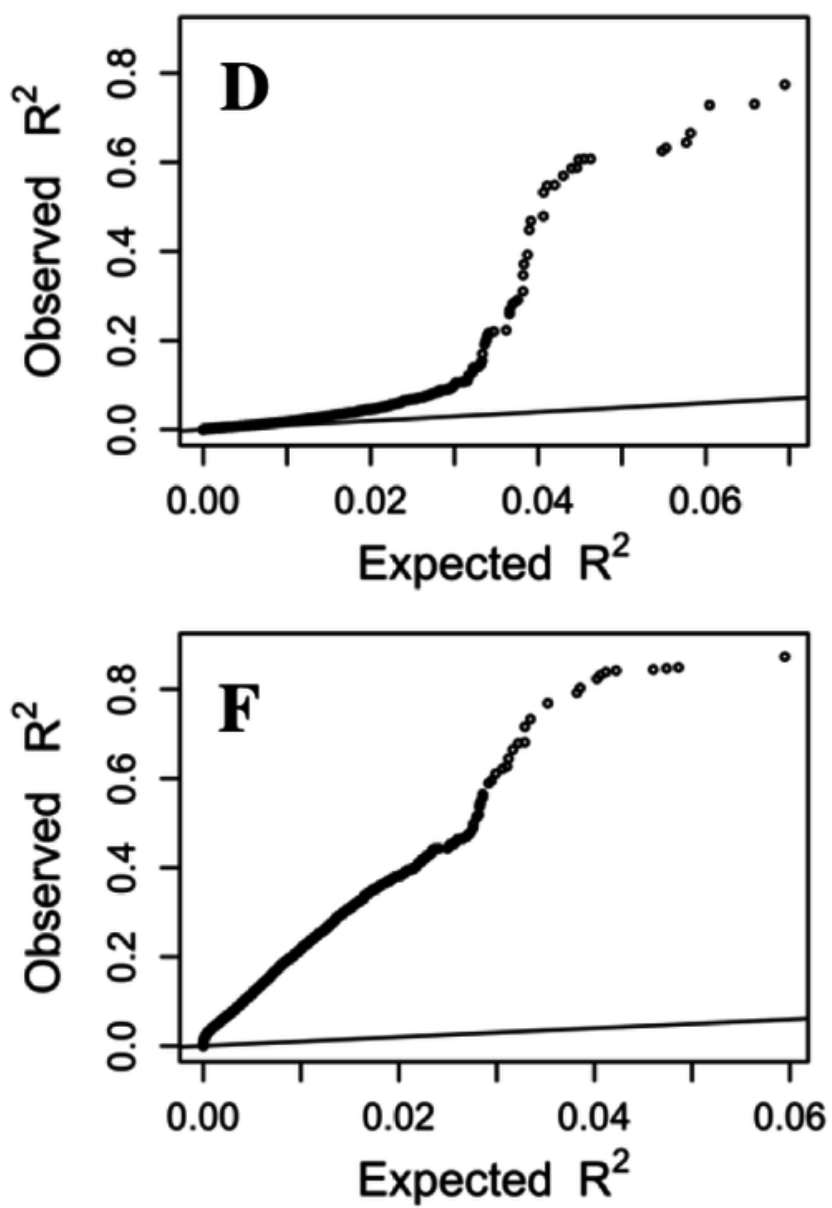


\section{Figure 4}

Comparison of $\mathrm{R}^{2}$ from using methylation probes, $\mathrm{S} \& \mathrm{C}$ probes and all probes.

LASSO regression $R^{2}$ values from three datasets, Adipose $(A, B), P B M C(C, D)$ and $L C L(E, F)$, were generated from methylation probes (black line), $S \& C$ probes (blue points), and all probes (red points). The $95 \%$ confidence interval of $R^{2}$ from methylation probes is shown as grey shadow. 

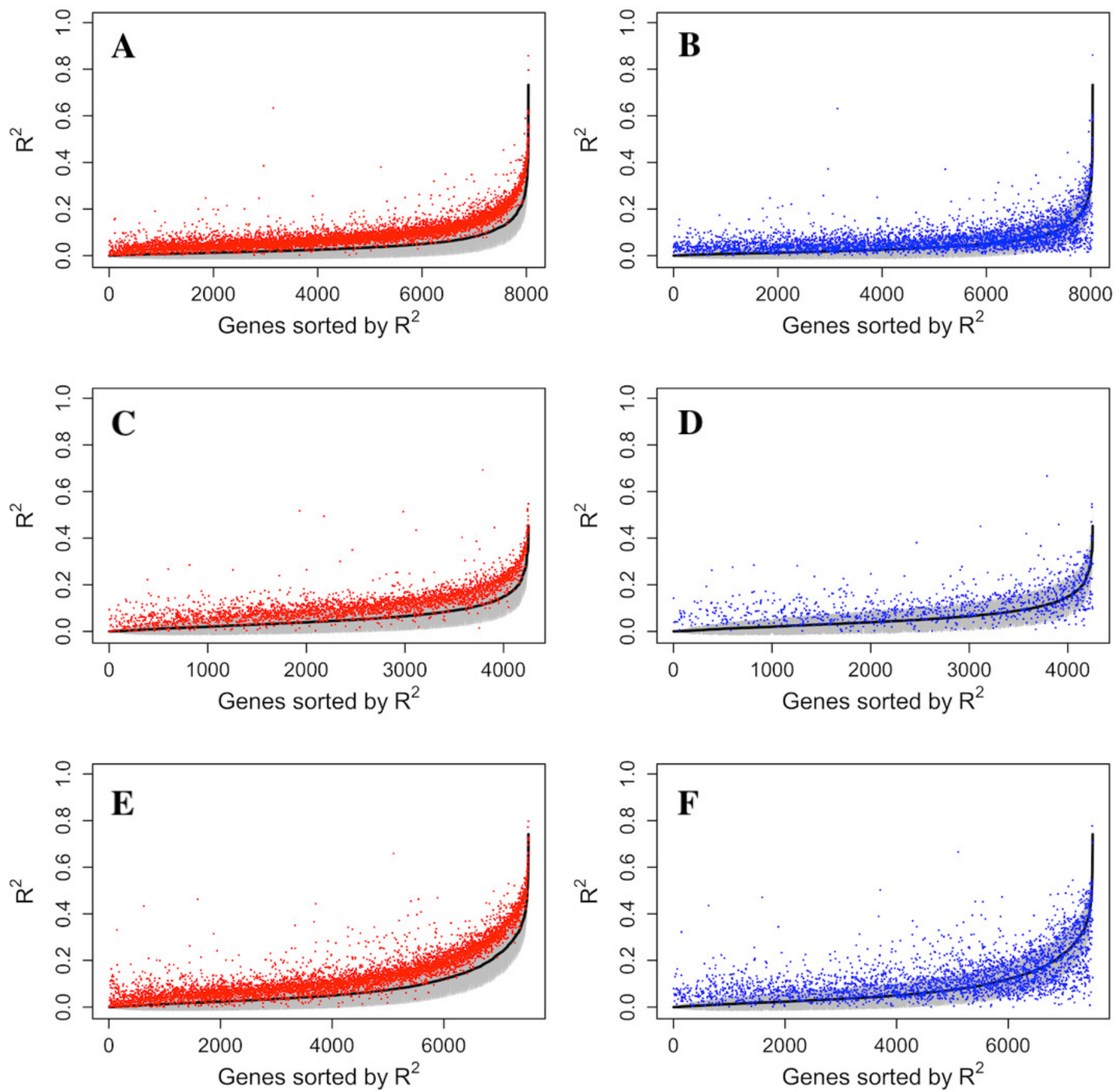


\section{Figure 5}

Example genes with high prediction power.

$\mathrm{R}^{2}$ is from LASSO regression models. Adipose, PBMC and LCL are the three datasets. methyl, methylation probes; all, all probes. X-axis indicates the predicted expression levels from LASSO regression models, $y$-axis was observed expression levels for each dataset. 
PAX8
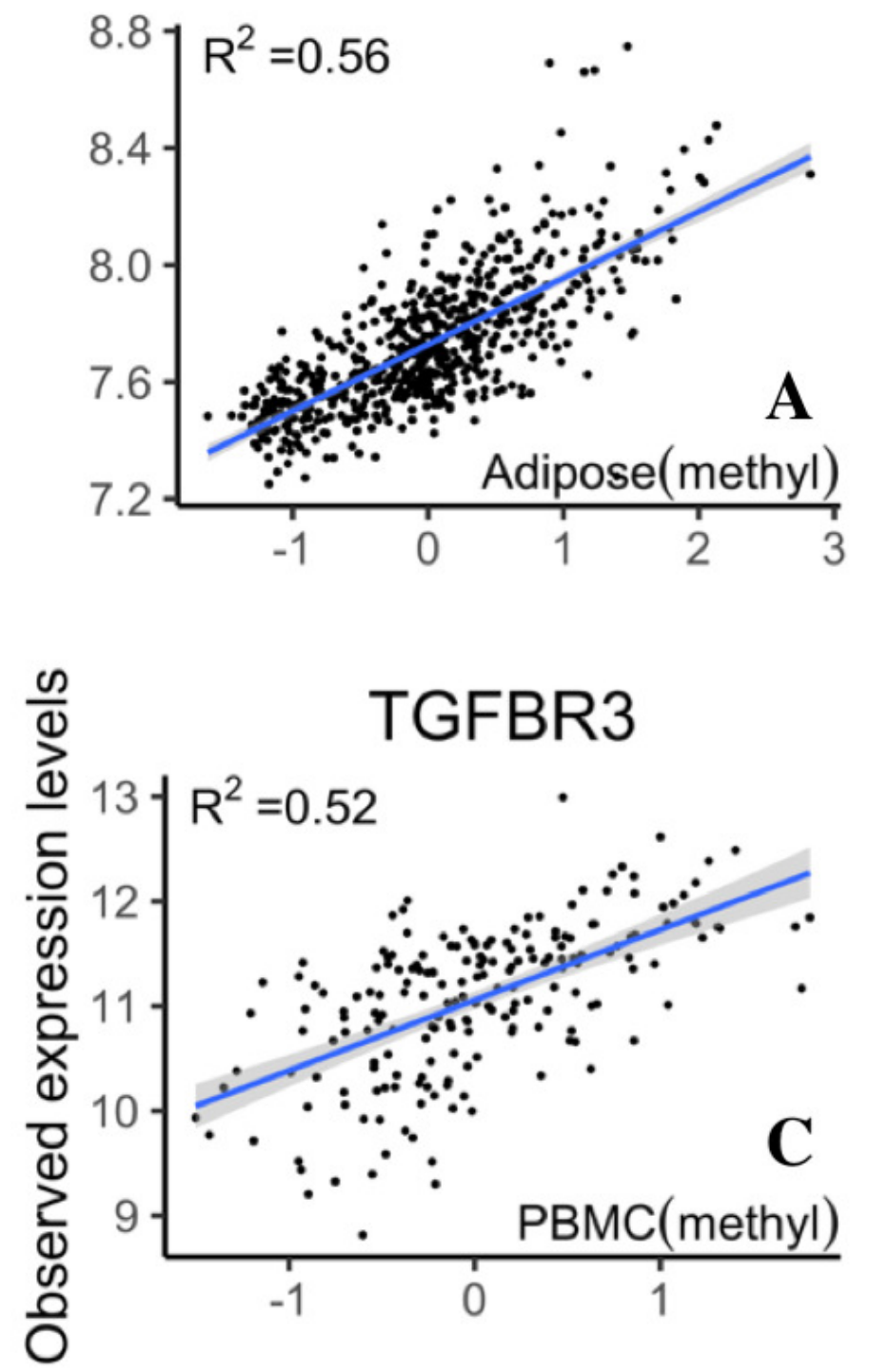

GTSF1

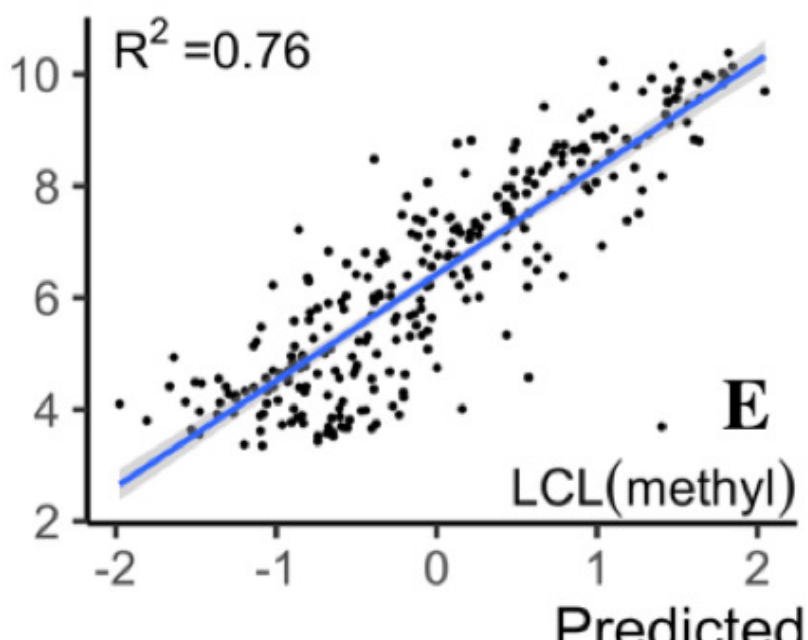

HLA-DRB5

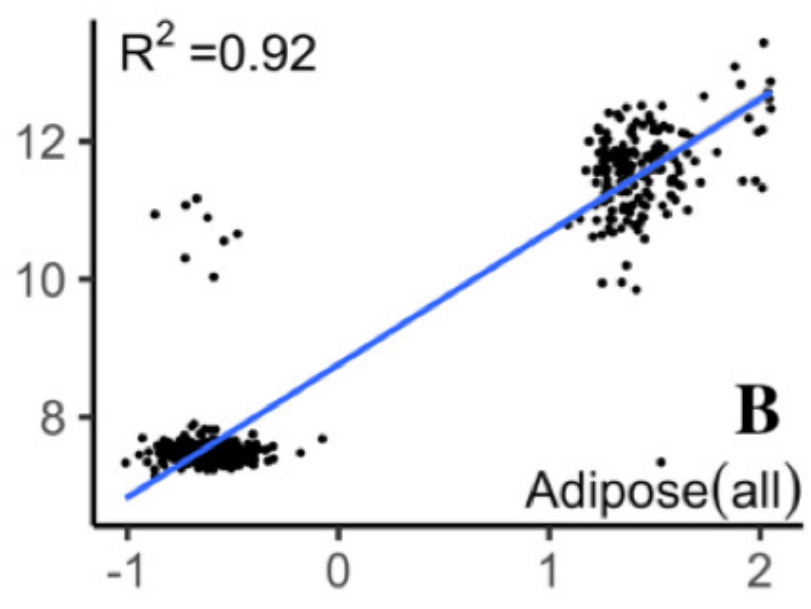

DDX3Y

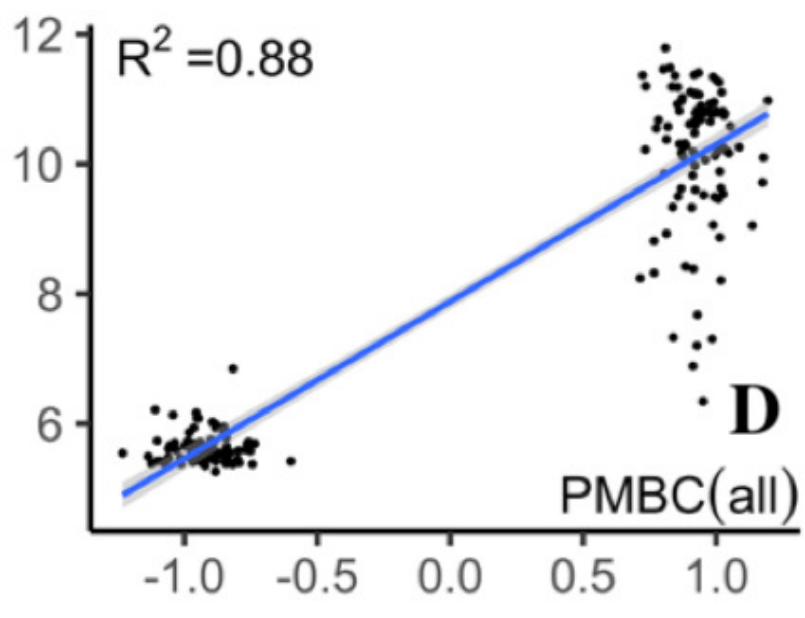

XIST

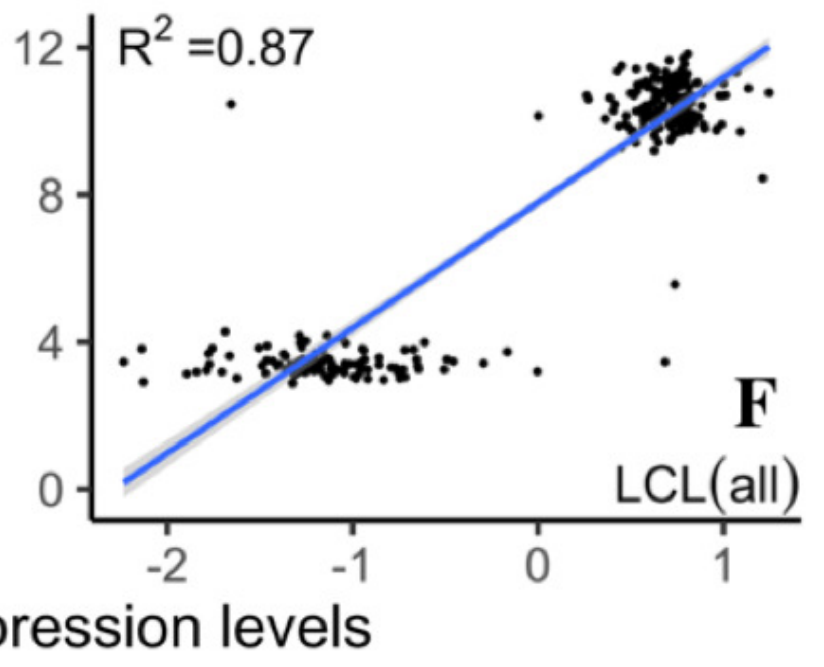




\section{Table $\mathbf{1}$ (on next page)}

The number of genes with prediction $\mathrm{R}^{2}$ larger than thresholds in single, multiple and LASSO regressions.

"All Genes": the total number of genes in a dataset after quality control and normalization. "Genes w/ LASSO model": the number of genes with valid LASSO models. 


\begin{tabular}{|c|c|c|c|c|c|c|c|c|c|c|}
\hline & \multirow{2}{*}{ Dataset } & \multirow{2}{*}{$\begin{array}{c}\text { Regress } \\
\text { Model }\end{array}$} & \multicolumn{3}{|c|}{ Model Fitting $\mathrm{R}^{2}$} & \multicolumn{3}{|c|}{ Cross Validation $\mathrm{R}^{2}$} & \multirow{2}{*}{$\begin{array}{l}\text { Genes } \\
\text { w/ } \\
\text { LASSO } \\
\text { model }\end{array}$} & \multirow{2}{*}{$\begin{array}{l}\text { All } \\
\text { Genes }\end{array}$} \\
\hline & & & $>0.1$ & $>0.2$ & $>0.3$ & $>0.1$ & $>0.2$ & $>0.3$ & & \\
\hline \multirow{9}{*}{ 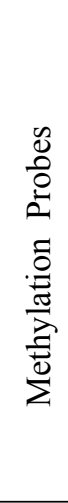 } & \multirow{3}{*}{ Adipose } & Single & 486 & 87 & 19 & 106 & 16 & 2 & \multirow{3}{*}{8040} & \multirow{3}{*}{26736} \\
\hline & & Multiple & 2178 & 476 & 116 & 722 & 166 & 38 & & \\
\hline & & LASSO & 1702 & 360 & 113 & 827 & 179 & 42 & & \\
\hline & \multirow{3}{*}{ PBMC } & Single & 851 & 108 & 14 & 381 & 33 & 4 & \multirow{3}{*}{4252} & \multirow{3}{*}{31030} \\
\hline & & Multiple & 3358 & 1163 & 382 & 746 & 109 & 30 & & \\
\hline & & LASSO & 2382 & 561 & 142 & 1022 & 165 & 30 & & \\
\hline & \multirow{3}{*}{ LCL } & Single & 1753 & 465 & 126 & 419 & 82 & 21 & \multirow{3}{*}{7514} & \multirow{3}{*}{32946} \\
\hline & & Multiple & 5138 & 2170 & 975 & 1663 & 575 & 185 & & \\
\hline & & LASSO & 4246 & 1740 & 805 & 2030 & 751 & 258 & & \\
\hline \multirow{9}{*}{ 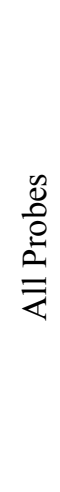 } & \multirow{3}{*}{ Adipose } & Single & 591 & 115 & 33 & 103 & 21 & 5 & \multirow{3}{*}{8864} & \multirow{3}{*}{26736} \\
\hline & & Multiple & 3037 & 760 & 211 & 898 & 226 & 64 & & \\
\hline & & LASSO & 2283 & 536 & 178 & 1008 & 259 & 76 & & \\
\hline & \multirow{3}{*}{ PBMC } & Single & 1330 & 212 & 58 & 666 & 90 & 34 & \multirow{3}{*}{5064} & \multirow{3}{*}{31030} \\
\hline & & Multiple & 4455 & 1902 & 694 & 994 & 197 & 64 & & \\
\hline & & LASSO & 3207 & 870 & 235 & 1465 & 289 & 66 & & \\
\hline & \multirow{3}{*}{ LCL } & Single & 1888 & 533 & 155 & 425 & 88 & 32 & \multirow{3}{*}{7498} & \multirow{3}{*}{32946} \\
\hline & & Multiple & 5870 & 2573 & 1267 & 1757 & 627 & 221 & & \\
\hline & & LASSO & 4646 & 2029 & 999 & 2155 & 840 & 335 & & \\
\hline
\end{tabular}

2 